\title{
Patient Safety Culture Status and Its Predictors among Healthcare Workers
}

\author{
Mengistu Mitiku', Alemseged Aregay ${ }^{2}$, Tesfay Hailu ${ }^{3}$ \\ ${ }^{1}$ Department of Health Systems, School of Pubic Health, College of Health Sciences, Mekelle University, Ethiopia \\ ${ }^{2}$ Department of Reproductive Health, School of Pubic Health, College of Health Sciences, Mekelle University, Ethiopia \\ ${ }^{3}$ Department of Epidemiology, School of Pubic Health, College of Health Sciences, Mekelle University, Ethiopia
}

\begin{tabular}{|c|c|}
\hline Article Info & ABSTRACT \\
\hline Article history: & \multirow{10}{*}{$\begin{array}{l}\text { Good patient safety culture of healthcare professionals brings about fine } \\
\text { consequences for patients. This study, therefore, aimed in evaluating the } \\
\text { current status and predictors of safety culture among healthcare workers in } \\
\text { Mekelle Zone hospitals, Tigray, Northern Ethiopia. A cross-sectional survey } \\
\text { was conducted among } 325 \text { healthcare workers in three hospitals of Mekelle } \\
\text { city from February to May, 2017. Simple random sampling technique was } \\
\text { employed to select study subjects. Data was analyzed using SPSS. Logistic } \\
\text { regression was used to determine the predictors of patient safety culture } \\
\text { among healthcare workers at 95\% confidence level and } 5 \% \text { level of } \\
\text { significance. Statistical significance was set at p <0.05. Of the } 325 \\
\text { Healthcare workers, } 21.6 \% \text { rated the culture of patient safety as satisfactory } \\
\text { and } 78.4 \% \text { rated as unsatisfactory. Old aged healthcare workers (AOR=21.9, } \\
95 \% \text { of CI: } 2.51-61.69 \text { ) and 'hospital management support for patient safety' } \\
\text { (AOR=2.68, } 95 \% \text { CI=1.06-6.79) were strong predictor of satisfactory patient } \\
\text { safety culture. Satisfactory patient safety culture grade obtained was only } \\
21.6 \% \text {, indicating that health care professionals are not delivering patient } \\
\text { centered service and there is a lot of work to be done in the hospitals to } \\
\text { improve culture of patient safety among healthcare workers. }\end{array}$} \\
\hline Received Feb 24, 2018 & \\
\hline Revised May 3, 2018 & \\
\hline Accepted Jun 30, 2018 & \\
\hline Keyword: & \\
\hline Health care workers & \\
\hline Hospital & \\
\hline Mekelle city & \\
\hline Northern Ethiopia & \\
\hline Safety culture & \\
\hline
\end{tabular}

Copyright () 2018 Institute of Advanced Engineering and Science. All rights reserved.

\section{Corresponding Author:}

Mengistu Mitiku,

Department of Health Systems,

Mekelle University,

Etiopia-Witten Road, Kebelle 03, Mekelle, Ethiopia.

Email: mengistu.mitiku@yahoo.com

\section{INTRODUCTION}

Patient safety culture is the product of individual and group values, attitudes, perceptions, competencies, and patterns of behaviour that determine the commitment to, and the style and proficiency of, an organization's health and safety management [1], [2] or as "freedom from accidental injury due to medical care, or medical errors [3]. Globally, though assessments of patient safety culture among health care facility workers is not done, it is estimated that positive scores of patient safety culture dimensions among health care professionals in the United States of America and China was 75\% and 73\%, respectively [4], [5]. Similarly, estimates of satisfactory patient safety culture among health professionals in the Eastern Mediterranean region, Lebanon, was found to be $71.5 \%$ [6]. In Ethiopia, there was no nation-wide study done so far. However, the assessment of health professionals' culture of patient safety in Jimma University Specialized Hospital, Ethiopia in 2012 showed that $27.9 \%$ of the study participants had expressed a satisfactory result [7].

The root causes of poor patient safety result are generally classified as human factors and system failures in health care delivery [1], [3], [8]. In developing countries, the cause of poor patient safety culture in health care facilities is multi-factorial and includes poor leadership and management, weak teamwork, 
absence of evidence-based practice, lack of communication and organizational learning. The relative contribution of each of these factors to poor patient safety culture of healthcare workers during service delivery varies greatly by health facility size, profession diversity, and health care workers experience and age [8], [9].

Due to poor patient safety culture, worldwide estimates show that in developed countries as many as one in 10 patients is harmed while receiving hospital care. Hundreds of millions of patients are affected by this worldwide each year [9]. Poor health care professionals' patient safety culture, which ranges from poor leadership and management support to poor attitude of individuals, is a problem that brings about bad consequences of patients in health care facilities. Report has indicated that hundreds of millions of patients are affected due to poor patient safety culture of health care workers worldwide each year [10], [11].

Since the launch of the WHO Patient Safety Programme in 2004, over 140 countries have worked to address the challenges of unsafe care due to poor health care workers patient safety culture [8], 10]. Likewise, Ethiopia's Federal Ministry of Health (FMOH) has been leading a sector-wide reform effort aimed at significantly improving the quality and safety of services at all levels of the country's decentralized health system [12]. Despite decades of proposed solutions, the existence of poor patient safety culture among health facility workers has continued and patients in developing and developed countries are still bumped into unnecessary consequence to clients due to poor culture of health professionals. The present study was, therefore, proposed to verify the existing information gap and come up with findings which might highlight the nature of patient safety culture among health professionals in the three hospitals of Mekelle city, two of them being the largest hospitals in Northern Ethiopia.

\section{RESEARCH METHOD}

\subsection{Study Setting and Period}

The study was conducted from February-April, 2016 in three government hospitals of Mekelle city, namely Ayder, Mekelle and Quiha hospitals which contain 1881, 541 and 196 staff numbers, respectively [13].

\subsection{Study Design and Sample Size Determination}

A cross-sectional study was conducted to assess the status \& predictors of patient safety culture among healthcare workers in Mekelle Zone Hospitals, Tigray, Ethiopia. Healthcare workers who were permanent employees of the study hospitals were included from this study. The sample size was determined according to a formula based on a comparison of the predicted mean score of the positive patient safety culture grade (Jimma's 63.9\% was considered) [7], setting the sample size so that differences between groups would be detected with a power of $80 \%$ and taking the assumption of $5 \%$ margin of error and $95 \%$ confidence interval, $10 \%$ non-response rate and 0.05 confidence level.

\subsection{Sampling Method and Technique}

Stratified random sampling technique was used to select healthcare professionals from different units or departments of the study hospitals. Population proportional to size was used to allocate the study subjects to the respective departments. Finally, a simple random sampling technique was used to select healthcare workers from the different departments of the study hospitals.

\subsection{Data Collection Tool}

The tool used for this study was adapted from the original tool developed by Agency for Healthcare Research and Quality, USA in 2004 and other studies [14-18]. The questionnaire was finally translated into Amharic language and back to English language to ensure consistency of its content. The translation was then reviewed by professionals from Medicine and Nursing Schools of College of Health Sciences of Mekelle University. This self-administered questionnaire, measuring 10 dimensions of safety culture and background data of the participating healthcare providers was given to representative sample of healthcare providers in the three hospitals by three BSc nurses supervised by one chief nurse. For staffs who failed to understand the questionnaire easily, the questionnaire was delivered as an interview by the data collectors. Data was collected from February to April, 2016. All items of the questionnaire were developed based on the 5-point Likert's response scale of agreement (strongly disagree to strongly agree) or frequency (never to always). In addition, there is one item outcome variable (Patient safety grade: measured with a five-point scale, from 'excellent' (5) to 'failing' (1). The tool consists of the following patient safety culture dimensions and participant background's related variables as independent variables and patient safety grade as outcome variable. 


\subsection{Data Management and Quality Control}

One day training on the purpose of the study, contents of the questionnaire, interviewing methods, confidentiality and other relevant issues was given to data collectors and supervisors. During the training, data collectors were assessed for their interviewing skills and understanding of the contents of the questionnaire. The quality of the data was assured by proper design and pre-testing of the questionnaire and training of the interviewers on data collection procedures. Every day, $10 \%$ of the completed questionnaires was randomly selected, reviewed and checked for completeness and relevance by the principal investigator and the necessary feedback was given to data collectors in the next morning. Incomplete questionnaires were identified and refilled.

\subsection{Data Analysis}

Data was entered, cleaned and analysed using SPSS version 20. The tool which contained 35 items that measure 10 dimensions included both positively and negatively worded items. Items were scored using a five-point scale reflecting the agreement rate on a five-point frequency scale (both including a neutral category). The percentage of positive responses for each item and composite were calculated. Negatively worded items were reversed when computing per cent positive response. To make the analysis easy, the outcome variable was dichotomized by collapsing its levels ('Strongly disagree', 'disagree' and 'acceptable' are regarded as levels referring unsatisfied patient safety culture grade and the levels 'very good' and 'excellent' were considered as levels referring satisfactory grade). After counting percent positive responses per composite, this number is divided by the total number of responses for this composite to obtain a percent positive response. Composite level scores were computed by summation of the items within the composite scales and dividing by the number of items with non-missing values. Cronbach's alpha which ranged from 0.58 to 0.84 was used to measure the internal consistency of the 10 composites.

Uni-variate analysis was also done to summarize demographic characteristics of hospitals and respondents. Bi-variate analysis was performed to derive potential variables to be included in the multivariate analyses. The variables found significant at 0.05 level of significance were examined by Multivariate logistic regression analysis to control for confounding factors at a $95 \%$ confidence interval and to determine the independent predictors for patient safety culture grade.

\subsection{Ethical Considerations}

Before starting the data collection process, ethical clearance was obtained from the institutional review board of Mekelle University, College of Health Sciences. Data collection was then conducted after explaining the aim and its possible benefits to the study participant and to the study hospitals' administrations. Consent was obtained after explaining their right not to participate if they would not be comfortable. Then, after obtaining consent from the study subject, interviewing was conducted.

\section{RESULTS AND ANALYSIS}

\subsection{Socio-Demographic Characteristics of the Study Subjects}

A total of 325 informed and consented healthcare workers who were working at three governmental hospitals of Mekelle city were enrolled in this study of which $176(54.2 \%)$ were females and $147(45.8 \%)$ were males with a response rate of $99.38 \%$. Majorities $(61.5 \%)$ of the participants were recruited from Ayder referral hospital and $88 \%$ were in the age category less than 45 years. The majority $(77.5 \%)$ were Bachelor of Science holders. With regard to profession, the majority $(46.8 \%)$ of the respondents were nurses are presented in Table 1.

\subsection{Patient Safety Culture Score}

Patient safety culture grade of the departments or units of the study hospitals was given by the study participants. In view of that, $21.6 \%$ of participants rated as satisfactory and $78.4 \%$ rated as unsatisfactory. For the purpose of analysis by logistic regression, the categories of the dependent variable were dichotomized in to "satisfactory" and "unsatisfactory". Satisfactory represents the categories 'excellent and very good' whereas unsatisfactory represents to the categories 'acceptable, poor and failing'. Figure 1 shows Patient safety culture status as rated by Health care workers in Mekelle city public hospitals, 2017. 
Table 1. Socio-Demographic Characteristics of Healthcare Workers

\begin{tabular}{|c|c|c|}
\hline Characteristics & Number & Percent \\
\hline \multicolumn{3}{|l|}{ Sex } \\
\hline Female & 149 & 45.8 \\
\hline Male & 176 & 54.2 \\
\hline \multicolumn{3}{|l|}{ Age } \\
\hline$<30$ years & 173 & 53.2 \\
\hline $30-45$ & 113 & 34.8 \\
\hline $46-55$ & 39 & 12.0 \\
\hline \multicolumn{3}{|l|}{ Profession } \\
\hline Physician & 50 & 15.4 \\
\hline Nurse & 152 & 46.8 \\
\hline Laboratory technician/technologist & 39 & 12 \\
\hline Pharmacy & 24 & 7.4 \\
\hline Others & 60 & 18.5 \\
\hline \multicolumn{3}{|l|}{ Department } \\
\hline Emergency department & 69 & 21.2 \\
\hline Outpatient department & 187 & 57.5 \\
\hline Inpatient department & 69 & 21.2 \\
\hline \multicolumn{3}{|l|}{ Educational level } \\
\hline 10th grade complete & 5 & 1.5 \\
\hline 12th grade complete & 6 & 1.8 \\
\hline Diploma & 48 & 14.8 \\
\hline Degree & 252 & 77.5 \\
\hline Masters & 14 & 4.3 \\
\hline \multicolumn{3}{|l|}{ Work experience } \\
\hline Less than one year & 49 & 15.1 \\
\hline $1-5$ years & 157 & 48.3 \\
\hline $6-10$ years & 94 & 28.9 \\
\hline $11-15$ years & 22 & 6.8 \\
\hline Above 15 years & 3 & 0.9 \\
\hline \multicolumn{3}{|l|}{ Working hours per week } \\
\hline Less than 20 hours & 3 & 0.9 \\
\hline 20-39 hours & 48 & 14.8 \\
\hline 40-59 hours & 233 & 71.7 \\
\hline $60-79$ hours & 18 & 5.5 \\
\hline 80-99 hours & 23 & 7.1 \\
\hline \multicolumn{3}{|l|}{ Participants role in the hospital } \\
\hline Supervisory role & 77 & 23.7 \\
\hline Non-supervisory role & 248 & 76.3 \\
\hline
\end{tabular}

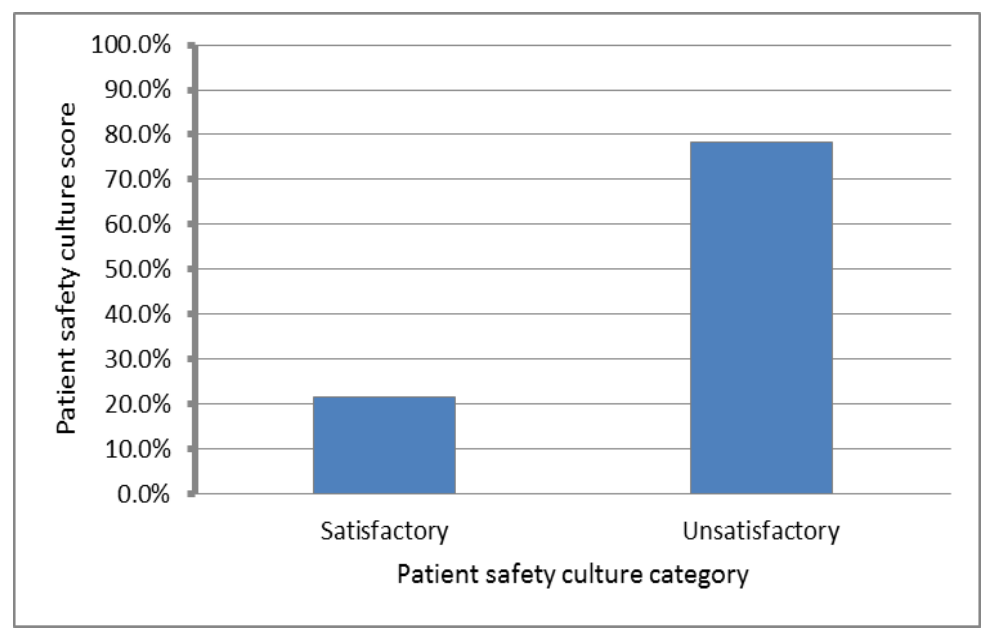

Figure 1. Patient safety culture status as rated by health care workers

\subsection{Culture Composites and Items Distribution of Positive Responses and Scores}

The ten culture dimensions were computed to pinpoint areas of strength (those where per cent positive rating exceeds 75\%) and those requiring improvement (scores below 50\%) [2]. Accordingly, no cultural dimension considered area of strength was found. All dimensions have reflected a score which regards them as areas requiring improvements with the dimensions ' non-punitive response to error, staffing 
and hospital management support for patient safety culture' pinpointed as the least three is presented in Table 2.

Table 2. Cronbach's Alpha and Distribution of Positive Responses and Scores for Survey Composites and Items

\begin{tabular}{|c|c|c|}
\hline Composites and Survey Items & $\begin{array}{l}\text { Average } \% \text { positive } \\
\text { response }\end{array}$ & $\begin{array}{c}\text { Mean (Standard } \\
\text { deviation) }\end{array}$ \\
\hline Supervisor expectations of patient safety (Cronbach's $\alpha=0.633$ ) & 58.2 & \\
\hline $\begin{array}{l}\text { 1. My supervisor/manager says a good word when he/she sees a job done according } \\
\text { to established patient safety procedures }\end{array}$ & 59.7 & $3.39(1.17)$ \\
\hline $\begin{array}{l}\text { 2. My supervisor/manager seriously considers staff suggestions for improving } \\
\text { patient safety }\end{array}$ & 60.3 & $3.33(1.13)$ \\
\hline $\begin{array}{l}\text { 3. Whenever pressure builds up, my supervisor/manager wants us to work faster, } \\
\text { even if it means taking shortcuts }\end{array}$ & 36.3 & $3.03(1.26)$ \\
\hline $\begin{array}{l}\text { 4. My supervisor/manager overlooks patient safety problems that happen over and } \\
\text { over }\end{array}$ & 76.3 & $4.09(1.11)$ \\
\hline Organizational learning and continuous improvement (Cronbach's $\alpha=0.593$ ) & 47.1 & \\
\hline $\begin{array}{l}\text { 5. We are actively doing things to improve patient safety } \\
\text { 6. Mistake have led to positive changes here } \\
\text { 7. After we make changes to improve patient safety, we evaluate their effectiveness } \\
\text { Teamwork within units (Cronbach's } \alpha=0.925 \text { ) }\end{array}$ & $\begin{array}{c}68 \\
33.5 \\
39.7 \\
71.8\end{array}$ & $\begin{array}{l}3.84(1.04) \\
2.96(1.19) \\
3.12(1.14)\end{array}$ \\
\hline 8. Staff support one another in this unit & 75.1 & $3.91(0.97)$ \\
\hline $\begin{array}{l}\text { 9. When a lot of work needs to be done quickly, we work together as a team to get } \\
\text { the work done }\end{array}$ & 75.1 & $3.93(0.85)$ \\
\hline 10. In this unit, people treat each other with respect & 68.6 & $3.72(1.03)$ \\
\hline $\begin{array}{l}\text { 11. When members of this unit get really busy, other members of the same unit help } \\
\text { out }\end{array}$ & 68.3 & $3.64(0.95)$ \\
\hline Non-punitive response to error(Cronbach's $\alpha=0.802)$ & 36.8 & \\
\hline 12. Staff feel like their mistakes are held against them (R) & 32.9 & $3.02(1.17)$ \\
\hline $\begin{array}{l}\text { 13. When an event is reported, it feels like the person is being written up, not the } \\
\text { problem }(\mathrm{R})\end{array}$ & 39.7 & $3.09(1.09)$ \\
\hline 14. Staff worry that mistakes they make are kept in their personnel file (R) & 37.8 & $3.1(1.10)$ \\
\hline Staffing(Cronbach's $\alpha=0.644$ ) & 35.8 & \\
\hline 15. We have enough staff to handle the workload & 24.9 & $2.46(1.20)$ \\
\hline 16. Staff in this unit work longer hours than is best for patient care & 42.2 & $3.27(1.33)$ \\
\hline 17. We use agency/temporary staff than is best for patient care (R) & 64.6 & $3.70(1.26)$ \\
\hline 18. When the work is in "crisis mode" we try to do too much, too quickly (R) & 11.7 & $2.31(1.17)$ \\
\hline Hospital management support for patient safety (Cronbach's $\alpha=0.457$ ) & 37.4 & \\
\hline 19. Hospital management provides a work climate that promotes patient safety & 32.9 & $2.64(1.20)$ \\
\hline 20. The actions of hospital management show that patient safety is a top priority & 32 & $2.67(1.21)$ \\
\hline $\begin{array}{l}\text { 21. Hospital management seems interested in patient safety only after an adverse } \\
\text { event happens (R) }\end{array}$ & 47.4 & $3.56(1.10)$ \\
\hline Teamwork across hospital units (Cronbach's $\alpha=0.587$ ) & 51.2 & \\
\hline 22. There is good cooperation among hospital units that need to work together & 60.3 & $3.45(0.98)$ \\
\hline 23. Hospital units work well together to provide the best care for patients & 67.7 & $3.53(1.05)$ \\
\hline $\begin{array}{l}\text { 24. Hospital units do not coordinate well with each other and this might affect patient } \\
\text { care (R) }\end{array}$ & 43.7 & $3.24(1.27)$ \\
\hline 25. It is often not easy to work with staff from other hospital units (R) & 32.9 & $2.97(1.05)$ \\
\hline Hospital handoffs \& transitions(Cronbach's $\alpha=0.830$ ) & 45.8 & \\
\hline $\begin{array}{l}\text { 26. Things "fall between the cracks", i.e., things might go uncontrolled and get lost } \\
\text { (ex: medical records, medical treatment, patient information and education, } \\
\text { discharge criteria) when transferring patients from one unit to another (R) }\end{array}$ & 30.2 & $2.88(1.19)$ \\
\hline 27. Important patient care information is often lost during shift changes $(\mathrm{R})$ & 51.7 & $3.3(1.28)$ \\
\hline 28. Problems often occur in the exchange of information across hospital units (R) & 39.4 & $3.15(1.16)$ \\
\hline 29. Shift changes are problematic for patients in this hospital & 61.8 & $3.49(1.27)$ \\
\hline Communication openness(Cronbach's $\alpha=0.65$ ) & 39.8 & \\
\hline $\begin{array}{l}\text { 30. Staff will freely speak up if they see something that may negatively affect patient } \\
\text { care }\end{array}$ & 56.9 & $3.45(1.09)$ \\
\hline 31. Staff feel free to question the decisions or actions of those with more authority & 29.5 & $2.72(1.23)$ \\
\hline 32. Staff are afraid to ask questions when something does not feel right & 33.5 & $2.85(1.24)$ \\
\hline Feedback and communications about error(Cronbach's $\alpha=0.87$ ) & 41.3 & \\
\hline 33. We are given feedback about changes put into place based on event reports & 33.8 & $2.58(1.24)$ \\
\hline 34. We are informed about errors that happen in this unit & 43.4 & $2.83(1.28)$ \\
\hline 35. In this unit, we discuss ways to prevent errors from happening again & 46.8 & $2.98(1.38)$ \\
\hline
\end{tabular}




\subsection{Predictors of Patient Safety Culture}

In the bivariate analysis, the factors that were associated with patient safety culture grade include age (greater than 45 years) and all patient safety culture dimensions except 'non-punitive response to error'. Compared to healthcare professionals in the age category 'less than 30 years', those in the age category greater than 45 years' $(\mathrm{OR}=3.45,95 \% \mathrm{CI}=1.13-10.5)$ had higher odds of reporting satisfactory patient safety culture grade. Moreover, a one unit increase on most patient safety culture dimensions increased odds of reporting better patient safety culture grades. In fact, patient safety grades increased by 2.97 (95\% $\mathrm{CI}=1.96-4.51)$ for every unit increase in Supervisor/Manager expectations \& actions promoting patient safety, 2.09(95\% CI=1.45-3.01) for every unit increase in Organizational learning and continuous improvement, $2.28(95 \% \mathrm{CI}=1.52-3.42)$ for every unit increase in teamwork within units, $1.52(95 \%$ $\mathrm{CI}=1.07-2.16)$ for every unit increase in staffing, 3.61(95\% CI=2.45-5.33) for every unit increase in hospital management support for patient safety culture, $2.72(95 \% \mathrm{CI}=1.58-4.68)$ for every unit increase in teamwork across hospital units, 2.23 (95\% CI=1.59-3.14) for every unit increase in hospital handoffs \& transitions, 2.04 (95\% CI=1.43-2.92) for every unit increase in communication openness and 2.77 (95\% $\mathrm{CI}=1.97-3.90)$ for every unit increase in feedback and communications about error.

Multiple logistic regression analysis result showed that health care professionals in the age category 'greater than 45 years' $(\mathrm{AOR}=21.9,95 \% \mathrm{CI}=2.51-61.69)$ and 'hospital management support for patient safety' $(\mathrm{AOR}=2.68,95 \% \mathrm{CI}=1.06-6.79)$ were significantly associated with patient safety culture grade is presented Table 3 .

Table 3. Multivariate Analysis of Predictors of Patient Safety Culture Grade

\begin{tabular}{|c|c|c|c|c|}
\hline \multirow[b]{2}{*}{ Variable } & \multicolumn{2}{|c|}{ Patient safety culture grade } & \multirow[b]{2}{*}{ COR $(95 \% \mathrm{Cl})$} & \multirow[b]{2}{*}{ AOR $(95 \% \mathrm{Cl})$} \\
\hline & $\begin{array}{l}\text { Satisfactory } \\
(\mathrm{n}=70)\end{array}$ & $\begin{array}{l}\text { Unsatisfactory } \\
(\mathrm{n}=255)\end{array}$ & & \\
\hline \multicolumn{5}{|l|}{ Sex } \\
\hline Female & $45(25.6 \%)$ & $131(74.4 \%)$ & 1 & 1 \\
\hline Male & $25(16.7 \%)$ & $124(83.3 \%)$ & $0.58(0.34-1.01)$ & $0.73(0.22-2.36)$ \\
\hline \multicolumn{5}{|l|}{ Age } \\
\hline Less than 30 years & $34(19.6 \%)$ & $139(79.4 \%)$ & 1 & 1 \\
\hline $30-45$ years & $32(28.3 \%)$ & $81(71.7 \%)$ & $2.14(0.71-6.43)$ & $9.03(0.87-93.17)$ \\
\hline $46+$ years & $4(10.2 \%)$ & $35(89.8 \%)$ & $3.45(1.13-10.5)^{*}$ & $21.90(2.51-61.69)^{*}$ \\
\hline \multicolumn{5}{|l|}{ Educational level } \\
\hline 12th grade complete and below & $4(33.3 \%)$ & $8(66.7 \%)$ & 1 & 1 \\
\hline Diploma & $20(28.9 \%)$ & $49(71.1 \%)$ & $1.87(0.36-9.57)$ & $0.30(0.00-11.02)$ \\
\hline Degree & $42(18.6 \%)$ & $183(81.4 \%)$ & $1.53(0.45-5.18)$ & $2.43(0.27-21.37)$ \\
\hline Masters and above & $4(21.1 \%)$ & $15(78.9)$ & $0.86(0.27-2.72)$ & $1.43(0.17-11.70)$ \\
\hline \multicolumn{5}{|l|}{ Healthcare workers experience } \\
\hline Less than 1 years & $6(12.2 \%)$ & $43(87.8)$ & 1 & 1 \\
\hline $1-5$ years & $30(19.1 \%)$ & $127(80.9 \%)$ & $0.27(0.02-3.56)$ & $0.69(0.01-25.45)$ \\
\hline $6-10$ years & $24(25.5 \%)$ & $70(74.5 \%)$ & $0.47(0.04-5.38)$ & $2.852(0.08-95.47)$ \\
\hline $11-15$ years & $9(40.9 \%)$ & $13(59.1 \%)$ & $0.68(0.05-7.90)$ & $2.35(0.05-98.63)$ \\
\hline Above 15 years & $1(33.3 \%)$ & $2(66.7 \%)$ & $1.38(0.10-17.67)$ & $0.88(0.02-33.82)$ \\
\hline \multicolumn{5}{|l|}{ Weekly duty hours } \\
\hline Less than 20 hours & $3(15.7 \%)$ & $16(84.3 \%)$ & 1 & 1 \\
\hline 20-39 hours & $6(12.5 \%)$ & $42(87.5 \%)$ & $0.91(0.20-3.99)$ & $1.83(0.10-32.41)$ \\
\hline 40-59 hours & $54(24.8 \%)$ & $163(75.2 \%)$ & $0.69(0.21-2.25)$ & $0.91(0.09-8.87)$ \\
\hline Greater than 60 hours & $7(17.1 \%)$ & $34(82.9 \%)$ & $1.60(0.67-3.84)$ & $3.04(0.42-21.58)$ \\
\hline \multicolumn{5}{|l|}{ Profession } \\
\hline Physician & $13(26 \%)$ & $37(74 \%)$ & 1 & 1 \\
\hline Nurse & $35(23 \%)$ & $117(77 \%)$ & $1.56(0.63-3.88)$ & $0.76(0.14-3.93)$ \\
\hline $\begin{array}{l}\text { Laboratory } \\
\text { technician/technologist }\end{array}$ & $4(10.2 \%)$ & $35(89.8 \%)$ & $1.33(0.62-2.83)$ & $0.56(0.12-2.55)$ \\
\hline Pharmacy & $7(29.1 \%)$ & $17(70.9 \%)$ & $0.50(0.15-1.73)$ & $0.71(0.09-5.60)$ \\
\hline Others & $11(18.3 \%)$ & $49(81.7 \%)$ & $1.83(0.61-5.49)$ & $0.75(0.10-5.43)$ \\
\hline \multicolumn{5}{|l|}{ Healthcare worker's role } \\
\hline Non-supervisor & $19(24.6 \%)$ & $58(75.4 \%)$ & 1 & 1 \\
\hline Supervisor & $51(20.5 \%)$ & $197(79.5 \%)$ & $1.26(0.69-2.31)$ & $0.42(0.10-1.63)$ \\
\hline \multicolumn{5}{|l|}{ Department } \\
\hline Emergency & $17(24.6 \%)$ & $52(75.4 \%)$ & 1 & 1 \\
\hline Outpatient & $40(21.3 \%)$ & $147(78.7 \%)$ & $1.40(0.63-3.18)$ & $2.95(0.51-16.93)$ \\
\hline Inpatient & $13(18.8 \%)$ & $56(81.2 \%)$ & $1.17(0.58-2.35)$ & $4.69(0.94-23.36)$ \\
\hline
\end{tabular}




\section{CONCLUSION}

The satisfactory result of patient safety culture score obtained was only $21.6 \%$. This indicates that there is a lot of work to be done in the hospitals to improve culture of patient safety among healthcare providers particularly though trainings.

Old aged healthcare providers are good predictors of satisfactory patient safety culture score and therefore good for provision of healthcare services.

\section{ACKNOWLEDGEMENTS}

We would like to acknowledge Mekelle University for securing ethical approval of this project through its Health Research Ethics Review Committee. We are also grateful to Tigray regional health bureau and the study hospitals for supporting the implementation of the research. We also thank data collectors for the valuable data they helped us gather during the data collection period, and the study subjects for their willingness to participate in this study.

\section{REFERENCES}

[1] Health Safety Commission. Organizing for Safety, Third Report, ACSNI Study Group on Human Factors. Sudbury: HSE Books, 1993.

[2] Nieva V, Sorra J. Safety culture assessment: A tool for improving patient safety in health care organizations. Qual Saf Health Care: 12:17-23, 2003.

[3] Institute of Medicine, To err is human: Building a safer health system, National Academy Press, Washington DC, 1999.

[4] Shigeru F, Kanako S, Shinya I, Yinghui W, Chiu-Chin H,Tomonori H., "The characteristics of patient safety culture in Japan, Taiwan and the United States", BMC Health Services Research, 13: 20, 2013.

[5] Yanli N, et al., "Hospital survey on patient safety culture in China", BMC Health Services Research, 13: 228, 2013

[6] Fadi E, Hani D, Diana J, Maha J., "Predictors and outcomes of patient safety culture in hospitals", BMC Health Serv Res, 11:45, 2011.

[7] Assefa T, Woldie M, Ololo S, Woldemichael K., "Patient safety practices and medical errors: Perception of health care providers at Jimma University Specialized Hospital, Southwest Ethiopia", Open Journal of Preventive Medicine, 2: 162-170, 2012.

[8] WHO Regional Committee for Africa, Patient safety in African health services: Issues and solutions. Yaoundé, Republic of Cameroon, 2008.

[9] World Health Organization, Fact sheet on patient safety, 2014.

[10] World Health Organization African region, Guide for developing national patient safety policy and strategic plan, 2014

[11] Christine E., Sammer, R., Kristine P, Karan P, Douglas A., Mains P, et al., "What is Patient Safety Culture? A Review of the Literature” Journal of Nursing Scholarship, 2009.

[12] Federal Democratic Republic of Ethiopia, "Ethiopian hospitals reform implementation guideline", 2:1214, 2010.

[13] Mekelle Health Office, Annual Health service report, Mekelle, 2014.

[14] Bodur S., Filiz E., "A survey on patient safety culture in primary healthcare services in Turkey", International Journal for Quality in Health Care, 21: 348-355, 2009.

[15] Robb G, Seddon M., "Measuring the safety culture in a hospital setting: a concept whose time has come" The New Zealand Medical Journal, 123, 2010.

[16] Singer J, Geppert J, Sinaiko A, Howard S, Park K., "The culture of safety: results of an organizationwide survey in 15 California hospitals", Qual Saf Health Care, 12: 112-118, 2003.

[17] Hellings J, Klazinga N, Vleugels N., "Challenging patient safety culture: survey results", International Journal of Health Care, 20: 620-632, 2007.

[18] Pauline Occelli, et al., "Development of a safety culture: Initial measurements at six hospitals in France", Journal of Healthcare risk management, 30:4, 2011. 